\title{
Un sábado en el mercado móvil"
}

\author{
Natalia Medina Abella** \\ (nataliamac94@gmail.com )
}

Etnografia corta recibida el 02/10/2015 y aprobado el 19/11/2015.

\section{Cómo citar este artículo:}

MEDINA ABELLA, Natalia (2015). “Un sábado en el mercado móvil”. En: Trans-pasando Fronteras, Núm. 8, pp. 113-117. Cali, Colombia: Centro de Estudios Interdisciplinarios, Jurídicos, Sociales y Humanistas (CIES), Facultad de Derecho y Ciencias Sociales, Universidad Icesi.

DOI: $10.18046 /$ retf.i8.2229

Entre el ruido incesante del tráfico, las canciones populares, el vaivén de los pies contra la tierra, se va conociendo la complejidad de un mundo permeado por los olores, los alimentos y las historias de aquellos que hicieron del móvil su forma de sustento. El mercado móvil supone una relación entre lo rural y lo urbano, pero más allá de esto, nos habla de formas de organización particulares, e interacciones propias de personas que parecen conocerse hace ya mucho tiempo. Es una ventana que nos permite hablar del trabajo informal, el rebusque, la solidaridad y los conflictos de intereses. Todo esto en un espacio que en apariencia parece volátil y efímero, pero que con el paso del tiempo se ha consolidado como una costumbre, un encuentro de diversidades.

* Etnografía elaborada en el marco del curso Integración y Exclusión Social del Departamento de Estudios Sociales de la Universidad Icesi, Cali, Colombia.

** Estudiante de Sociología y Antropología, Universidad Icesi. 


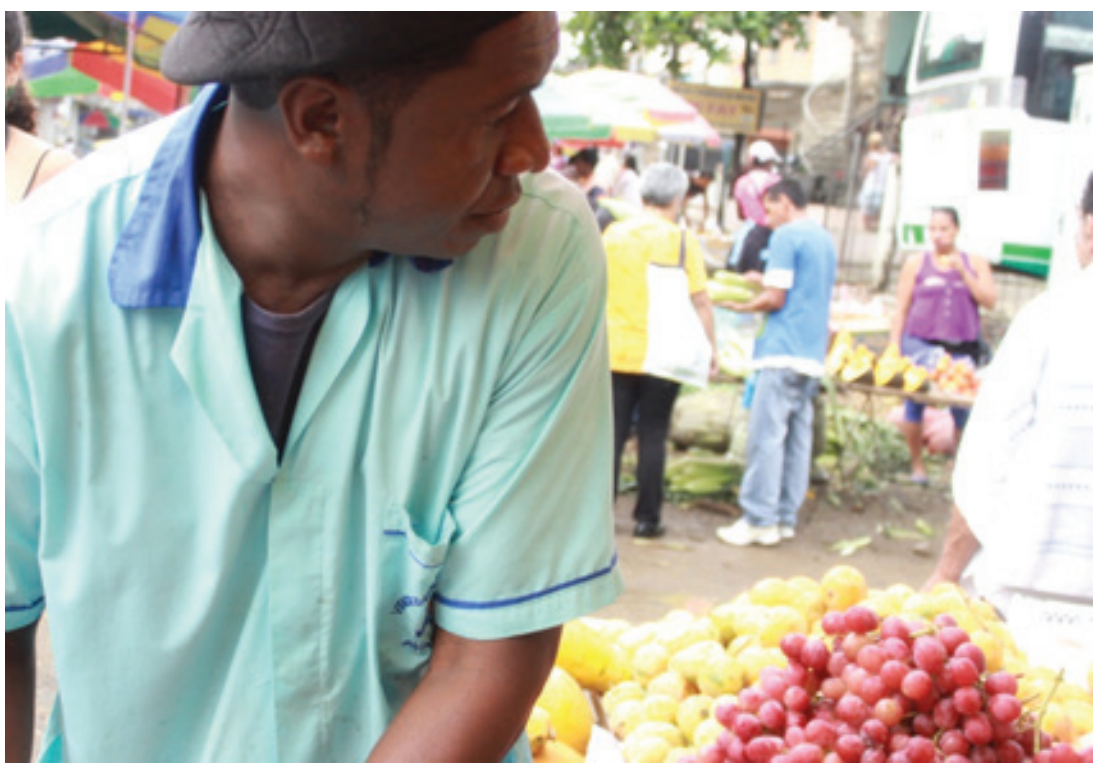

Foto tomada por el grupo de investigación de antropología visual, Universidad Icesi 2015

Mientras algunos caleños terminan la rumba de viernes en la noche, en el barrio Prados del Sur, se empiezan a escuchar los camiones cargados de mesas, sombrillas y alimentos. La llegada del mercado móvil se da antes de que el sol pueda salir por completo. El móvil es un evento semanal, todos los sábados desde hace más de veinte años, compradores y vendedores se acercan a la carrera 70 con calle 2 , a hacer parte de una galería que llega a su puerta. No solamente llena de frutas, verduras, carnes, utensilios café y otros insumos, sino también de una espacio relacional, permeado de confianza, amabilidad y trabajo colaborativo, que saca algunas buenas sonrisas, apodos y a veces uno que otro disgusto.

La creación de todos estos espacios (mercados móviles) alrededor de la ciudad, especialmente en las capas medias y bajas, representaban una forma de trabajo informal y de rebusque, fruto del desempleo, la falta de políticas de inclusión a las poblaciones más vulnerables y del despojo de algunos comerciantes que se ubicaban en el centro de la ciudad. Existen varias formas mediante las cuales se hace parte de esta práctica. Por un lado, se puede ser oferente o demandante de algún producto o 
servicio, en el primer caso, está la posibilidad de ser dueño o subempleado. Por otro lado, hay un grupo de hombres y niños que se encargan de las tareas colaborativas que surgen en las dinámicas de cada sábado. Esto sin negar todas las posibles conexiones que se entrelazan para que el mercado móvil sea posible.

Por los desniveles y el polvo de la calle principal del móvil, se mueven unos carritos de metal con una rueda a cada lado, sujetados por niños entre los once y quince años, que a cambio de una propina se encargan de llevar las compras de los clientes a los lugares de destino. Estos niños, en su mayoría afro, hacen parte de este panorama, casi como uno más de los que habitan esta práctica cotidiana, se inmiscuyen entre puesto y puesto, para ver quién puede necesitar su servicio, acostumbran a caminar en grupos o en parejas y los más pequeños suelen ser tímidos cuando están solos. El trabajo infantil se hace presente, nadie lo controla y nadie lo prohíbe, ellos están ahí. Quizá nadie se atreve, porque a nadie le parece del todo malo, a mí, por lo menos, me pone en un debate, entre la inmediatez y lo políticamente correcto, que se entrecruza con un sentimiento de culpabilidad, que aún no sé sopesar muy bien, pero que me pone de frente con una realidad innegable.

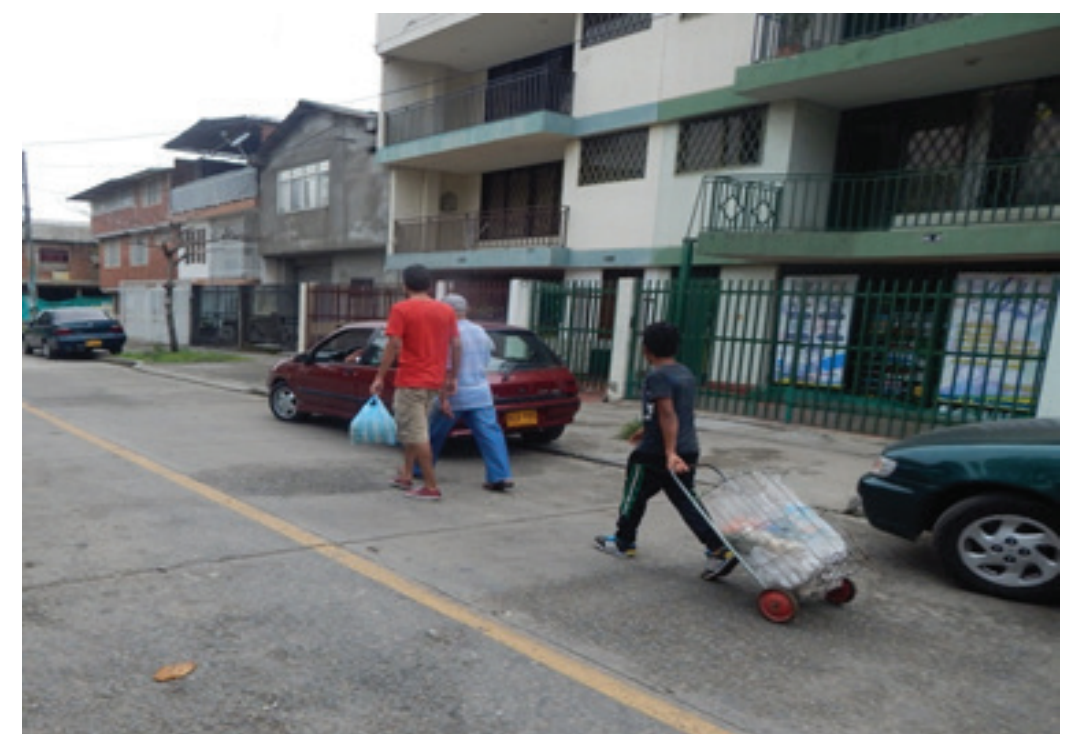

Foto tomada por el grupo de investigación de antropología visual, Universidad Icesi 2015 


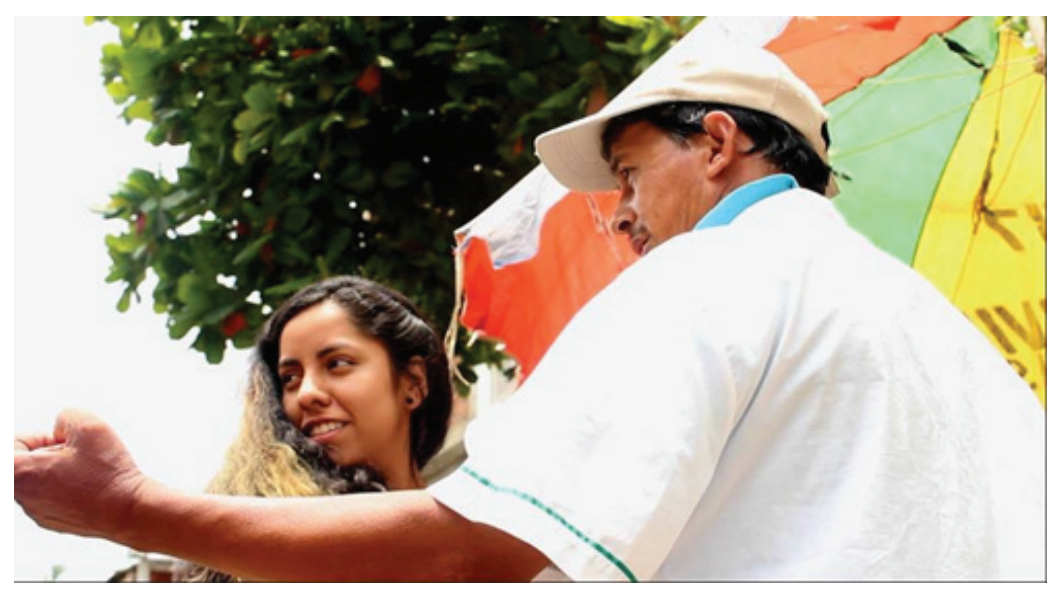

Foto tomada por el grupo de investigación de antropología visual, Universidad Icesi 2015

Los trabajadores del móvil, son mujeres y hombres muy valientes y resistentes, pues además de cargar con lo difícil y pesado de este oficio, que implica madrugar, trasnochar, cargar, recibir sol y otro sinfín de cuestiones que no saltan a la vista en un primer momento, han tenido que luchar contra algunas tensiones a la hora de realizar esta labor. El Estado, durante algún tiempo quiso acabar con los mercados móviles, por algunos problemas de salubridad, orden público e intereses que prefiero no mencionar. No obstante en 2001, la alcaldía de turno, expidió un decreto que legaliza esta actividad.

Así mismo, algunos vecinos de este móvil en particular, han creado acciones colectivas para presentarlas ante entidades gubernamentales con el fin de pedir la reubicación o finalización de las ventas que se llevan en frente de sus viviendas. Las basuras se convierten en el motivo perfecto para movilizar estas propuestas. Un sector cercano al móvil argumental que: "trabajen pero en otro lado Ellos no viven en este barrio". Algunas incomodidades de movilidad también parecen ser un punto importante para que las personas se opongan férreamente en contra del mercado. Sin embargo, hay otros habitantes que viven contentos con que el móvil éste en la puerta de sus casas, pues este trae productos frescos, buenos y económicos, que según Fabián, uno de los vecinos del barrio Prados del Sur, "es la misma verdura que te venden en los centros comerciales y almacenes de cadena, porque allá lo único que 
hacen es maquillar la fruta"; él también afirma que el tema de la basura propiciada por el móvil, es mentira, "en dos años que estoy acá, me parece que es falso, veo unos tipos que son los que barren esto y lo dejan otra vez limpio... yo nunca he visto que dejen la vaina sucia... yo creo que el que está diciendo eso está diciendo mentiras".

Al llevar mucho tiempo con este estilo de vida que implican los móviles, estas personas han constituido formas de organización particulares, que los llevan a agremiarse en una asociación que sea capaz de velar por los intereses, problemas y derechos de los y las vendedoras. Han creado una unión de personas que elige presidente y cargos administrativos, a través de elecciones democráticas, esto con el fin de consolidarse como una asamblea de asociados, empoderados en procesos que los afectan como comunidad. Además de esta parte institucional, trabajan de manera solidaria, aportando todos para recoger la basura que genera los residuos de los productos, y hacen cadenas ${ }^{1}$ con el fin de solventar algunos problemas financieros. Se han convertido en una comunidad multisituada, pues cada día de la semana se desplazan a otros lugares de la ciudad, pero siguen siendo los mismos vendedores, con las mismas relaciones y formas de integración que les permiten mantenerse, ante las fuerzas que tienen en contra. No hay que olvidar que también como grupo tiene diferencias, peleas y disgustos, pero que a pesar de eso, aún se mantiene lo más importante para que este grupo de personas mantenga vivo.

Probablemente, es por estas formas de exclusión por parte de algunos entes gubernamentales y de ciertos residentes aledaños, que la organización y los lazos de solidaridad e integración cada vez se ven más fortalecidos dentro del mercado móvil, pues podría entenderse como una forma de resistir a la constante idea de acabar con estos espacios dentro de la ciudad. En efecto, hay una necesidad latente de no perder la única forma de sustento que tienen ellos y ellas, por eso al hacer frente a las problemáticas que los cubren a todos y todas, resultan agrupándose no sólo para garantizar los mínimos de este trabajo, sino también para hacer de este oficio una quehacer ameno y digno.

1 Ahorro programado, donde por una sola vez cada uno de los que participa se hace acreedor de lo recolectado por todo el grupo. 